
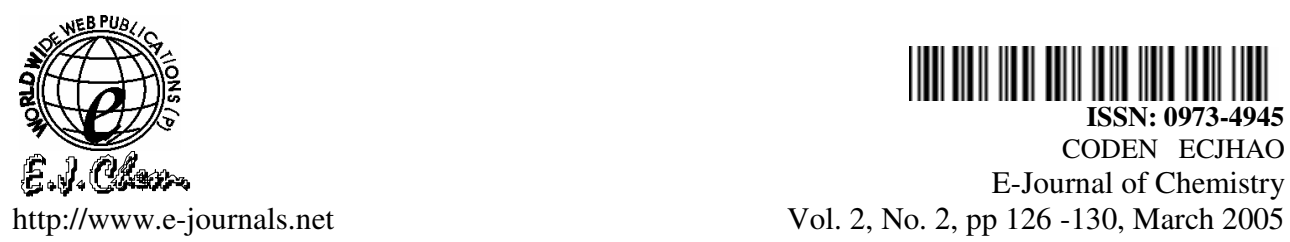

Vol. 2, No. 2, pp 126 -130, March 2005

\title{
Standardization Study of Antifertility Drug - Pippalyadiyoga
}

\author{
D. SHAILA*, M. K. SANTOSH, BISWAJIT CHOWDHURY, \\ I. RAJYALAKSHMI and I. SANJEEVARAO \\ Varun Herbals, 5-8-293/A, Mahesh Nagar, \\ Chirag Ali Lane, Hyderabad - 500001
}

Received 14 January 2005; Accepted 9 March 2005

\begin{abstract}
The present paper deals with the standardization study of pippalyadiyoga powder. It is used as a long acting contraceptive. The standardization of compound drug has been achieved by physico-chemical analysis and high performance liquid chromatography (HPLC) fingerprint studies. Quantitative evaluation of borax in pippalyadiyoga showed $19.08 \%$ as sodium borate. RP-HPLC was performed using methanol and water as mobile phase. The detection and quantification was performed at a wavelength of $345 \mathrm{~nm}$. Linearity of detector response for piperine was between the concentrations $0.005 \%$ to $0.1 \%$. The correlation coefficient obtained for the linearity was 0.998 . The recovery value of standard piperine was $99.4 \%$. Low value of standard deviation and coefficient of variation are indicative of high precision of the method. Quantitative evaluation of piperine in pippalyadiyoga was found to be $0.339 \%$.
\end{abstract}

Key words: Standardization, Pippalyadiyoga, HPLC and Antifertility Drug.

\section{Introduction}

Pippalyadiyoga is a herbo-mineral ayurvedic drug used as an antifertility formulation. The herbal components are pippali (Piper longum Linn., Piperaceae) and vidanga fruits (Embelia ribes Burm. f., Myrsinaceae) and a mineral component tankana (Borax) present in 1:1:1 ratio by weight. It is a long acting oral contraceptive ${ }^{1}$. The contraceptive effect of pippalyadiyoga was assessed which showed a good response and high antifertility effect ${ }^{2}$. Surva Mandal et al., have reported the organoleptic study, isolation and quantitative estimation of the active principles and thin layer chromatography study of pippalyadiyoga and its herbal components ${ }^{3}$. The piperine extracted from Piper nigrum Linn. was selected as the standard for identification of pepper in finished products or ayurvedic medicines. Piperine was subjected to TLC study along with finished products ${ }^{4}$. HPTLC study was performed for quantitative determination of piperine content from Piper nigrum Linn. ${ }^{5}$. So, in the present paper the physico- chemical and HPLC fingerprint study has been discussed. 


\section{Materials and Methods}

Pippalyadiyoga powder was supplied by the Head quarter of CCRAS (Central Council for Research in Ayurveda and Siddha), New Delhi, for chemical analysis and standardization study. Standard piperine was procured from M/s Sigma -Aldrich Chemie GmbH, Germany.

\section{Physico-chemical analysis}

The organoleptic study, $\mathrm{pH}$ (5\% aqueous), moisture content, total ash, alcohol soluble extractive, water soluble extractive, qualitative organic, inorganic and heavy metal (lead and arsenic) analysis and quantitative analysis of borax were carried out as per the standard procedures ${ }^{6-8}$.

\section{Preparation of sample}

The 5\% alcoholic extract of compound drug was prepared by soaking the material for $18 \mathrm{hr}$ in absolute alcohol. The extract was centrifuged at $3000 \mathrm{rpm}$ and then filtered through $0.2 \mu$ membrane filter using high-pressure vacuum pump.

\section{Calibration}

The standard piperine solution was prepared by dissolving $5 \mathrm{mg}$ of piperine in $5 \mathrm{ml}$ of absolute alcohol. Three additional calibration levels were prepared by diluting this solution with alcohol to obtain $0.005 \%, 0.01 \%, 0.02 \%$ and $0.1 \%$ concentrations for studying the linearity. The precision of the method was also studied by injecting a sample solution of concentration $0.01 \%$ five times and finding out the standard deviation and coefficient of variation.

\section{HPLC analysis}

A gradient HPLC (Shimadzu HPLC Class VP series) with two LC- 10 AT VP pumps (Shimadzu), variable wave length programmable photo diode array detector SPD-M10A VP (Shimadzu), CTO10AS VP column oven (Shimadzu), SCL-10A VP system controller (Shimadzu) and reverse phase Luna $5 \mu \mathrm{C}_{18}$ (2) Phenomenex column $(250 \mathrm{~mm} X 4.6 \mathrm{~mm})$ was used. The HPLC system was equipped with Class VP series version 6.1 software (Shimadzu). The mobile phase components methanol: water were filtered through $0.2 \mu$ membrane filter before use and were pumped from the solvent reservoir at a flow rate of $1 \mathrm{ml} / \mathrm{min}$ which yielded column backup pressure of $250-260 \mathrm{kgf} / \mathrm{cm}^{2}$. The initial Bpump concentration was $50 \%$. The column temperature was maintained at $27^{\circ} \mathrm{C}$. $20 \mu 1$ of respective sample was injected by using Rheodyne syringe (Model 7202, Hamilton).

\section{Results and Discussion}

The analytical data of pippalyadiyoga is tabulated in the Table-1. The powder of pippalyadiyoga was brown in color with aromatic odor and astringent taste. The $\mathrm{pH}$ of $5 \%$ aqueous solution was found to be 9.0 , moisture content $3.87 \%$, total ash content $30.15 \%$, alcohol soluble extractive $9.98 \%$ and water soluble extractive $42 \%$. The qualitative organic analysis of alcoholic extract of pippalyadiyoga powder showed the presence of alkaloids, glycosides, steroids, tannins and phenolic compounds. The powder showed the presence of calcium, iron, phosphate, sodium, magnesium, chloride, potassium, carbonate and borate. The assay for borax in pippalyadiyoga showed $19.08 \%$ as sodium borate. Heavy metal analysis showed negative result for arsenic and lead. It has been reported that the organoleptic characters of pippalyadiyoga showed grey color with pungent, bitter and astringent taste. The $\mathrm{pH}$ of aqueous solution of pippalyadiyoga reported to be $9-10$ (Universal $\mathrm{pH}$ paper) ${ }^{3}$.

Standard piperine solutions of $0.005 \%, 0.01 \%, 0.02 \%$ and $0.1 \%$ concentration analyzed for studying the linearity and the area count obtained for these solutions are presented in Table-2. Piperine showed good linearity in the concentration range of $0.005 \%-0.1 \%$ with a correlation coefficient of 0.998. The precision of the method was also studied by injecting a single sample solution five times (Table-3) and finding out the standard deviation and coefficient of variation. The standard deviation and coefficient of variation were found to be 0.161 and 0.219 .

The HPLC chromatogram of standard piperine at an optimum wavelength of $345 \mathrm{~nm}$ showed a mean area (Table-2) of 7328514.2 at a mean retention time of $23.733 \mathrm{~min}$ (Figure-1). The recovery 
value of standard piperine was $99.4 \%$. The HPLC chromatogram of pippalyadiyoga corresponding to standard piperine showed at a retention time of $23.061 \mathrm{~min}$ with an area of 9944671 at a wavelength of $345 \mathrm{~nm}$ (Figure-2). Quantitative evaluation of piperine in pippalyadiyoga showed $0.339 \%$. The HPLC analysis of methanolic extract of piperine isolated from Piper nigrum Linn. showed optimum wavelength at $343 \mathrm{~nm}^{3}$.

Table 1. Data of physico-chemical analysis of pippalyadiyoga

\begin{tabular}{lll}
\hline S. No. & Parameters & Pippalyadiyoga \\
\hline & & \\
1. & Color & Brown \\
2. & Odor & Aromatic \\
3. & Taste & Astringent \\
4. & $\mathrm{pH}(5 \%$ aqueous $)$ & 9.0 \\
5. & Moisture (\%) & 3.87 \\
6. & Ash $(\%)$ & 30.15 \\
7. & Alcohol Soluble Extractive $(\%)$ & 9.98 \\
8. & Water Soluble Extractive $(\%)$ & 42 \\
9. & Borax content $(\%)$ & 19.08 \\
10. & Alkaloid & $+\mathrm{ve}$ \\
11. & Glycoside & $+\mathrm{ve}$ \\
12. & Steroid & $+\mathrm{ve}$ \\
13. & Tannin & $+\mathrm{ve}$ \\
14. & Phenol & $+\mathrm{ve}$ \\
15. & Calcium & $+\mathrm{ve}$ \\
16. & Iron & $+\mathrm{ve}$ \\
17. & Phosphate & $+\mathrm{ve}$ \\
18. & Sodium & $+\mathrm{ve}$ \\
19. & Magnesium & $+\mathrm{ve}$ \\
20. & Chloride & $+\mathrm{ve}$ \\
21. & Potassium & $+\mathrm{ve}$ \\
22. & Carbonate & $+\mathrm{ve}$ \\
23. & Borate & $+\mathrm{ve}$ \\
24. & Arsenic & nil \\
25. & Lead & nil \\
& & \\
\hline & &
\end{tabular}

Table 2. Area counts for standard piperine

\begin{tabular}{lll}
\hline S. No. & Concentration of piperine $(\%)$ & Area counts \\
\hline & & \\
1. & 0.005 & 3752832 \\
2. & 0.01 & 7328721 \\
3. & 0.02 & 14495677 \\
4. & 0.1 & 67668536 \\
\hline
\end{tabular}


Figure 1. HPLC chromatogram of standard piperine

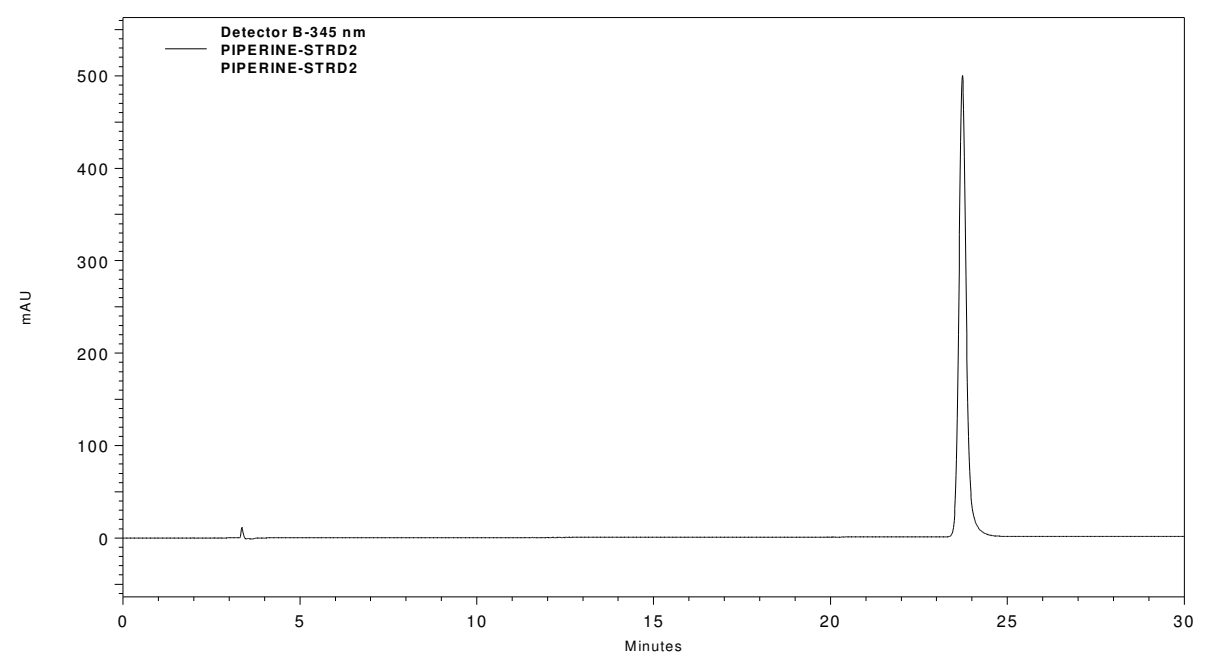

Figure 2. HPLC chromatogram of pippalyadiyoga

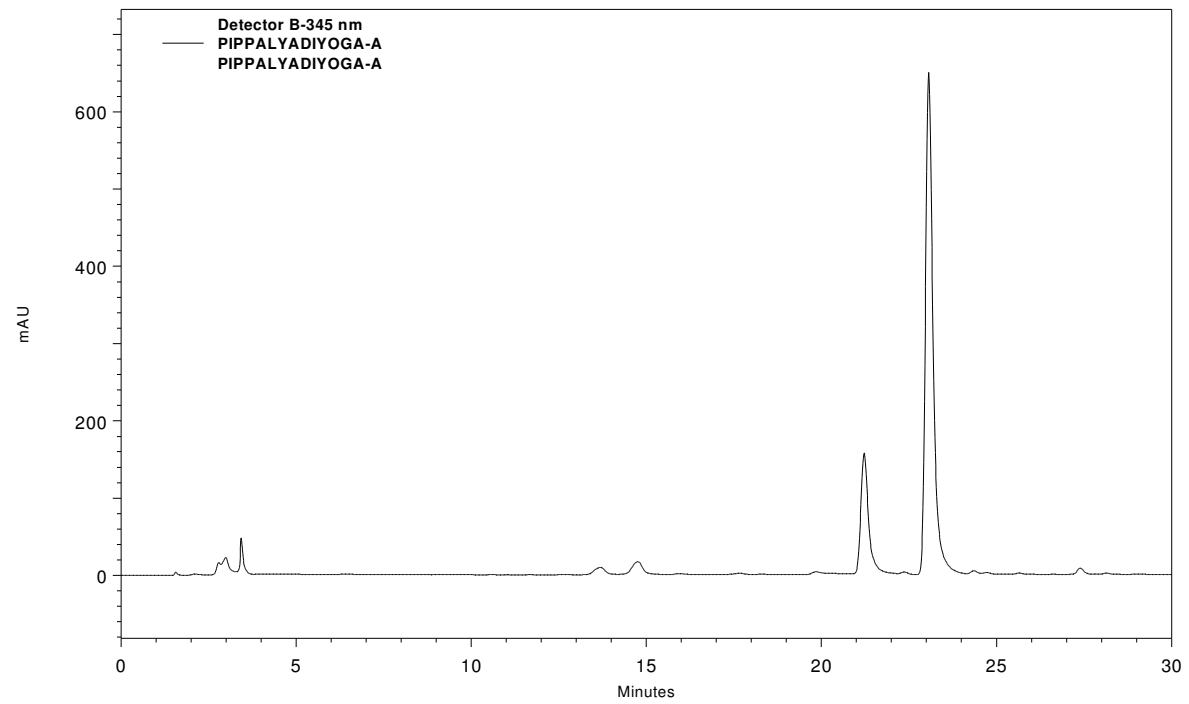

Table 3. Determination of standard deviation and coefficient of variation for standard piperine

\begin{tabular}{lcr}
\hline S. No. & Concentration of piperine $(\%)$ & Area \\
\hline 1. & 0.01 & 7328721 \\
2 & 0.01 & 7329368 \\
3 & 0.01 & 7330168 \\
4 & 0.01 & 7325643 \\
5 & 0.01 & 7328671 \\
\hline
\end{tabular}




\section{Conclusion}

The physico-chemical data and HPLC fingerprint profiles were evolved for pippalyadiyoga can be considered for fixing up standards.

\section{Acknowledgement}

The authors are thankful to the Director, Central Council for Research in Ayurveda and Siddha, New Delhi, for the financial support.

\section{References}

1. Asolakar L V, Kakkar K K and Chakre O J, Second Supplement to Glossary of Indian Medicinal Plants with Active Principles; Publications and Information Directorate, CSIR: New Delhi, 1992; Part I, 290.

2. Rawal J H and Shah M B, Pippalyadiyoga an unique herbal oral contraceptive drug, paper presented to the Seminar on Research in Ayurveda and Siddha; CCRAS: New Delhi, 20-22 March, 1995.

3. Surva Mandal, Ashes Das, Das P C, Majumdar C and Joshi P C, Bulletin of Medico EthnoBotanical Research 1999, 20(1-4), 102.

4. Thankamma A, Radhika L G and Soudamini C, Aryavaidyan, 1995, 8(3), 147.

5. Kulkarni D, Apte S P, Francis M and Sane R T, Indian Drugs, 2001, 38(6), 323.

6. Quality control methods for medicinal plant materials; WHO: Geneva, 1998.

7. Pharmacopoeial standards for ayurvedic formulations; CCRAS, Ministry of Health and Family Welfare: New Delhi, 1987.

8. Trease G E and Evans W C, Pharmacognosy; $11^{\text {th }}$ ed.; Bailliere Tindall: London, 1978. 


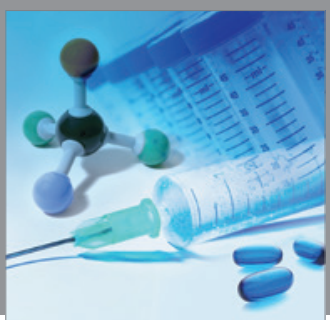

International Journal of

Medicinal Chemistry

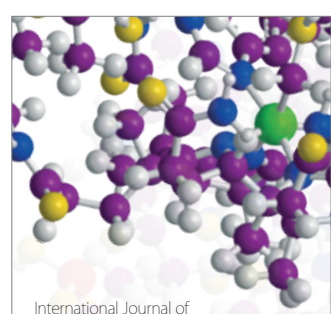

Carbohydrate Chemistry

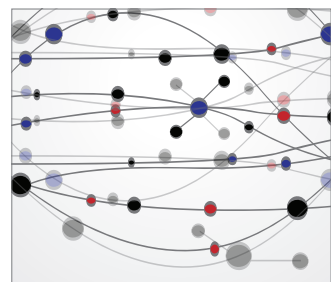

The Scientific World Journal
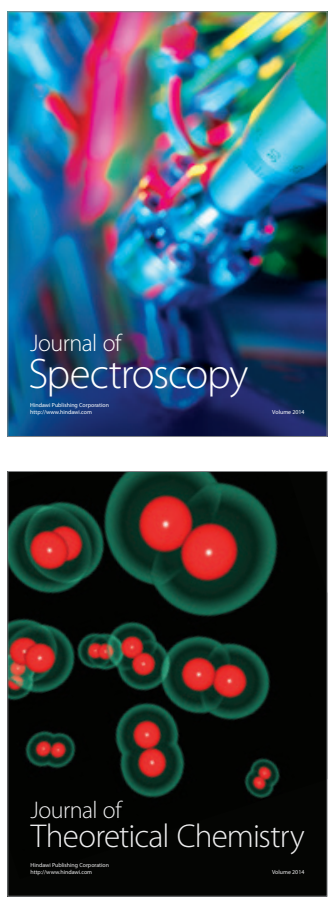
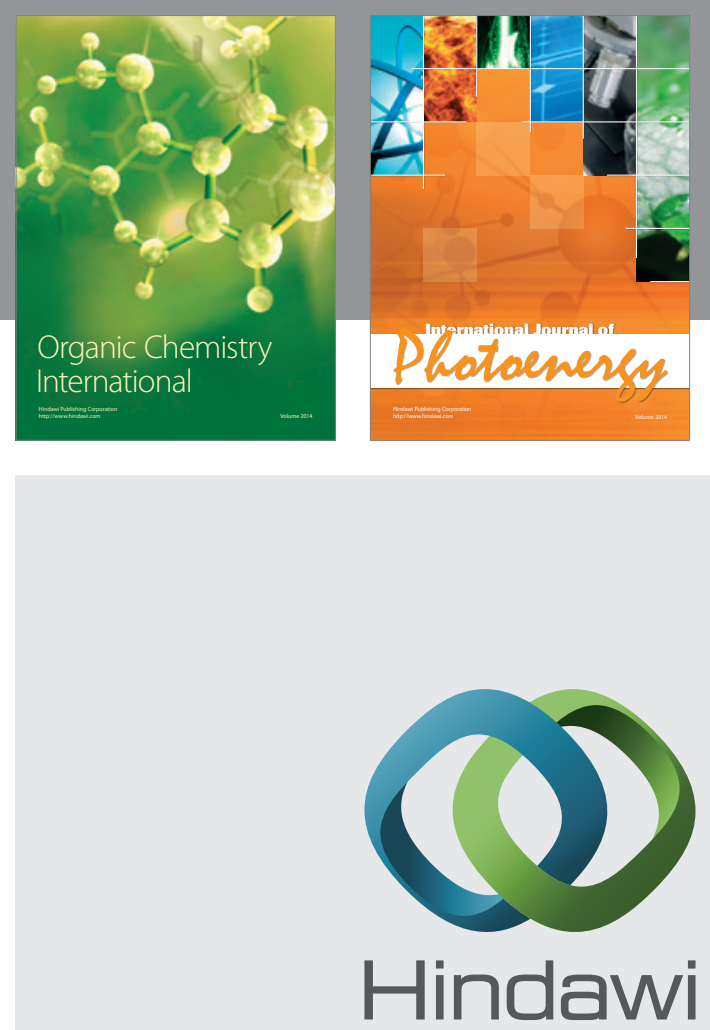

Submit your manuscripts at

http://www.hindawi.com
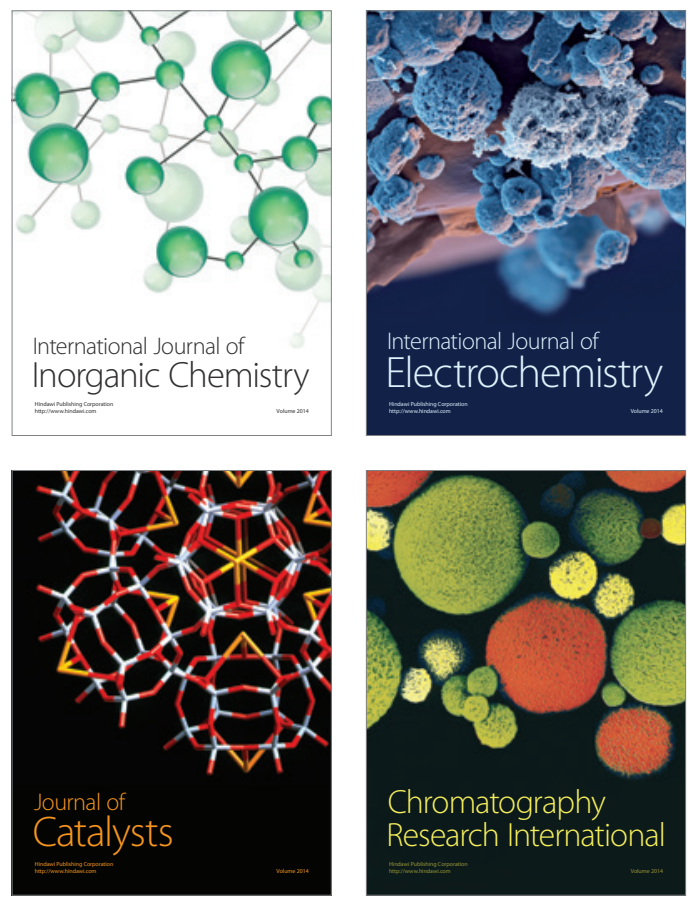
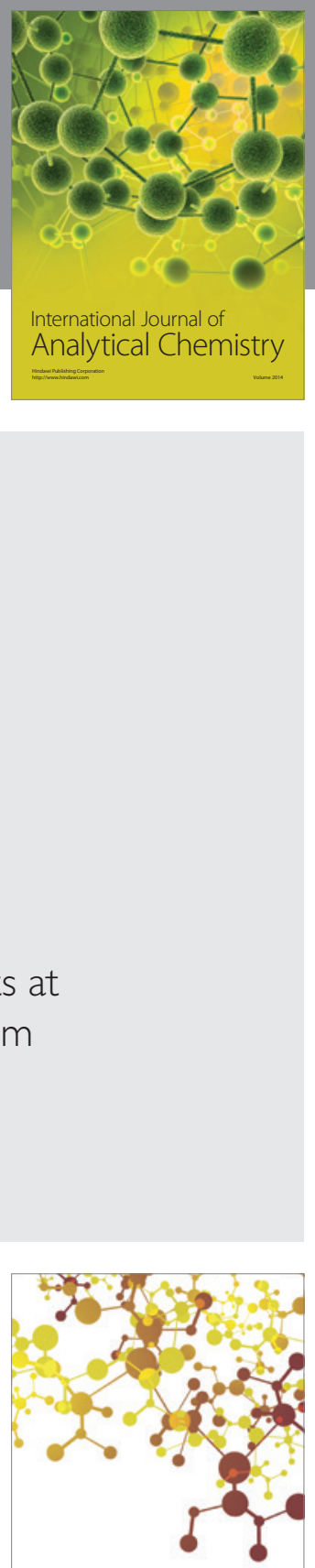

Journal of

Applied Chemistry
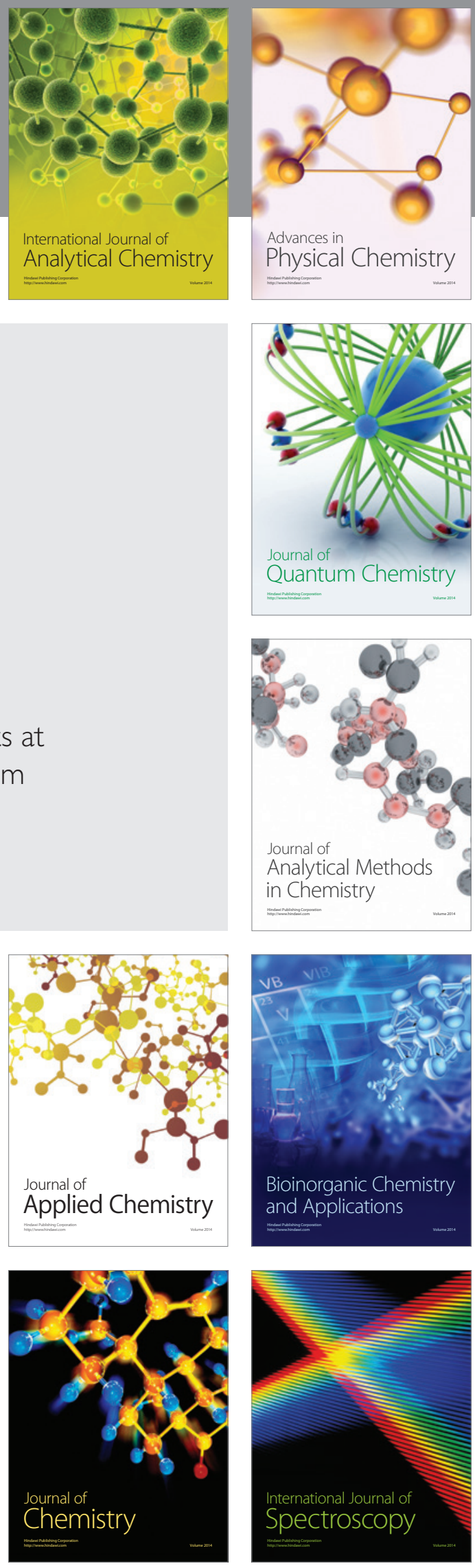